\title{
Correspondence
}

\section{Editorials should heed social scientists}

Your Editorials consistently recommend that policy decisions should be backed by sound science, including social science. However, my subjective analysis of a sample of these articles indicates that you do not always follow your own advice.

Roughly half of the 141 Editorials you published in the year from October 2012 relate to policy issues. Of these, only about $10 \%$ use literature citations to support their arguments. By contrast, $35 \%$ of the Editorials that express ideas with no direct bearing on policy are backed up by referencing.

Moreover, your policy proposals sometimes contradict the consensus opinion among social scientists. Take climatechange mitigation: you tend to highlight piecemeal emissionsreduction policies, such as the introduction of fuel standards, building codes or subsidies for renewable energy. However, most economists dismiss government micromanagement of polluting activities as inefficient and unfair, and would prefer to see the establishment of a universal carbon tax (see N. G. Mankiw East. Econ. J. 35, 12-23; 2009; and go.nature.com/ylxraf).

You also seem to overlook the diversity of opinion among social scientists on topical issues. For instance, you frequently make a plea for more power for the US Food and Drug Administration, without acknowledging the debate over whether the social good would be better served by increasing or decreasing the agency's regulatory power (see go.nature.com/pxxswg).

And in your persistent request for more government money for research, you could make a stronger case by using tools devised by social scientists to estimate the optimal size and allocation of science budgets.

Nature's views probably coincide with the default views of its readership and the public.
This should not distract you from publicizing instances of "sound science and evidence on a matter of public interest" (Nature 491, 160;2012).

Marcelino Fuentes University of A Coruña, Spain.

marcelinofuentes@gmail.com

\section{Virtual mobility can drive equality}

At a EuroScience Open Forum meeting last month, scientists, policy-makers and the public discussed 'virtual mobility'. Could it replace the conventional geographical mobility of earlycareer researchers between labs? (See also R. Garwood Nature 510, 313; 2014.)

The group concluded that virtual mobility would work, but should be combined with short-term visits to other labs to allow face-to-face contact, which in our view is crucial for building trust and for working across cultures. However, more than half of scientists questioned in a European Commission survey (www.more-2.eu) considered that virtual mobility would make short-term visits unnecessary.

Meeting participants agreed that virtual mobility would provide equal access to and for researchers with physical disabilities, would help those on parental leave to maintain contact with their national and international networks, and would enable researchers in poorer regions to access wellresourced labs and to collaborate internationally.

We maintain that virtual mobility should be considered on the same footing as mobility between disciplines, sectors and geographical regions, and that it should be seen as a driver of equal opportunities. Peer review and evaluation structures need to acknowledge these new mobility concepts.

Conor O'Carroll * European Research Area Steering Group on Human Resources and Mobility, Newry, Northern Ireland. ocarroll.conor@gmail.com * On behalf of 9 correspondents (see go.nature.com/emgqqffor full list).

\section{China is closing its rural education gap}

Schemes are already under way to address the education gap between China's urban and rural areas (see Q. Wang Nature 510, 445 ; 2014). These are improving education opportunities for rural students and supplying them with the best teachers.

For example, over the past ten years, the popular Go West programme has supplied more than 160,000 leading graduates to support the development of poor rural areas. The 17,500 positions provided this year cover several aspects, including teaching (see go.nature. com/lrhb6p; in Chinese). The Postgraduate Group of Volunteers to Support Education recruits teachers for rural regions from China's most prestigious universities, such as the Harbin Institute of Technology, and the non-governmental initiative Project Hope is helping to educate poor students.

More people from underdeveloped regions are enrolling in the country's leading universities, thanks to 185,000 government places allocated to students from these areas this year. And some nongovernmental organizations are contributing to educational institutions in deprived countryside areas; these include Our Free Sky, which provides teachers.

These efforts to close the education gap will be complemented by the gathering momentum of rural migration to China's cities (see X. Bai et al. Nature 509, 158-160; 2014). Xin Miao Harbin Institute of Technology, Harbin, China. xin.miao@aliyun.com Christina W. Y. Wong Hong Kong Polytechnic University, Kowloon, Hong Kong, China.

\section{Brain project leaders need an open mind}

As neuroscientists in Europe who care about the success of research projects large and small in our field, we are dismayed by the publicly reported attitude of the leaders of the Human Brain Project (HBP) towards scientists who have expressed widely supported criticisms of the project in an open letter (http://neurofuture.eu; see also Nature 511, 125 and 133-134; 2014).

Instead of acknowledging that there is a problem and genuinely seeking to address scientists' concerns, the project leaders seem to be of the opinion that the letter's 580 signatories are misguided.

The explicit supposition of the HBP leaders that some aspects of neuroscience research could be done in a different way than in the past deserves respect. However, mindful of the sincerity of a number of the well-regarded neuroscientists who have signed the letter as of 11 July, we submit that the likelihood of all $500+$ being misguided is remote.

A more enquiring and open-minded attitude to the concerns expressed may prove to be in the best interests of both the informationtechnology and neuroscience communities.

Richard Morris ${ }^{\star}$ University of Edinburgh, UK.

r.g.m.morris@ed.ac.uk ${ }^{*}$ On behalf of 6 correspondents (see go.nature.com $/ 8 \mathrm{nmm}$ du for full list).

CONTRIBUTIONS

Correspondence may be submitted to correspondence@nature. com after consulting the guidelines at http:// go.nature.com/cmchno. Alternatively, readers may comment online: www.nature.com/nature. 